\title{
Interpretación turística del Ágora Ateniense según la obra Descripción de Grecia de Pausanias
}

\author{
Fátima María Muñoz Tejero* \\ Universidad Rey Juan Carlos (España) \\ Nuria Morère Molinero** \\ Universidad Rey Juan Carlos (España)
}

\begin{abstract}
Resumen: El patrimonio arqueológico actual presenta una problemática que necesita respuesta inmediata. La descontextualización de los vestigios les otorga un carácter abstracto que dificulta su comprensión por parte del público inexperto. La Interpretación del Patrimonio (IP) actúa aquí como herramienta para solventar esta circunstancia, aportando significado y referencias funcionales y espacio-temporales a las fuentes arqueológicas, permitiendo la comprensión contextual del objeto (Hernández y Rojo, 2012). Por ende, la presente investigación utilizará esta disciplina para solucionar la problemática particular de uno de los recursos arqueológicos atenienses con más valor intrínseco, el Ágora Griega Antigua. Mediante el análisis del discurso histórico de Pausanias, uno de los viajeros más importantes de la Grecia Antigua, se desarrollará una modalidad de itinerario interpretativo a partir del análisis previo del recurso, creando una concepción turístico-patrimonial basada en la antigüedad, más auténtica y diferenciada de los productos estandarizados contemporáneos, posibilitando así el desarrollo turístico-arqueológico y la protección patrimonial.
\end{abstract}

Palabras Clave: Turismo arqueológico; Interpretación del Patrimonio; Grecia; Atenas; Pausanias.

Touristic Interpretation of the Athenian Agora based on the travel literature of Pausanias in his work "Description of Greece"

Abstract: Contemporary archaeological heritage presents difficulties that require immediate attention. The decontextualization of archaeological remains gives them an abstract dimension, which complicates their understanding by the non-expert public. Heritage Interpretation (HI) is therefore the tool to solve this issue. It enables individuals to understand the object in its full context, providing funtional and space-time references to archaeological sources (Hernández and Rojo, 2012). HI will be used in the research to solve the problem of the Ancient Greek Agora, one of the Athenian resources with the most intrinsic value. Through the analysis of this resource and the historical discourse of Pausanias, a significant traveller in Ancient Greece, an interpretative itinerary method is going to be developed. All previously stated arguments have as a main objective the creation of a more authentic concept of tourism and heritage, cemented in Ancient Times; which is differentiated from standardized products, and allows for tourism development and heritage protection.

KeyWords: Achaeological Tourism; Heritage Interpretation; Greece; Athens; Pausanias.

\section{Introducción.}

El legado ancestral de la Grecia contemporánea, producto de un pasado histórico que acunó el florecimiento de la civilización occidental, configura literalmente a este país como un vasto yacimiento arqueológico constructor de un turismo configurado como el sustento vital de un país ahogado por la

\footnotetext{
Graduada en Turismo por la Universidad de Córdoba y Máster en Dirección Internacional del Turismo por la Universidad Rey Juan Carlos (URJC). Actualmente cursa Doctorado en Turismo en la URJC; E-mail: fm.munozt@alumnos.urjc.es ** Profesora titular de Historia Antigua en la Universidad Rey Juan Carlos y catedrática acreditada; E-Mail: nuria. morere@urjc.es
} 
depresión socioeconómica. Sin embargo, como ocurre mayoritariamente con este tipo de patrimonio, su escasa interpretación ocasiona vestigios con un gran potencial intrínseco, pero mínimamente puestos en valor. La necesidad de contextualizar y dar significado a los mismos para su correcta dinamización y conservación, es el elemento perseguido con la presente investigación, imbricada alrededor de tres ejes principales: la Interpretación del Patrimonio (IP), el Turismo arqueológico, y el análisis de fuentes históricas para una mejor comprensión y explicación de los atractivos turísticos patrimoniales.

Tomando esto como premisa, el objetivo de nuestro estudio es el desarrollo de una propuesta interpretativa dinámica e innovadora, cimentada en la unión de un modelo teórico extraído de la doctrina de la IP (especificado posteriormente), y el análisis de fuentes literarias primarias, concretamente la obra "Descripción de Grecia" (s.II d.C.), del viajero griego Pausanias, mediante su aplicación al espacio arqueológico del Ágora Griega Antigua, localizado en Atenas.

\section{Marco Teórico}

La Interpretación del Patrimonio y cómo se configura para el Turismo es el marco teórico principal de nuestra investigación. Responde a la necesidad de dar significado y valor al patrimonio, debido a su carácter comunicativo, participativo, provocativo, y a su necesidad de adecuarse a una determinada audiencia mediante un discurso ameno, sencillo, impactante y personal. Asimismo, son cuatro elementos vertebradores de toda interpretación, que deben estar en constante interacción y equilibrio para el éxito del proceso interpretativo: el conocimiento del recurso o enclave, el público o audiencia al que nos dirigimos con el mensaje, las actividades a desarrollar, así como las técnicas interpretativas apropiadas.

Su origen se remonta a los trabajos de interpretación del medio natural de Muir (1896) y Mills (1920) en Norteamérica. Sin embargo, es con Tilden con quién se consolida esta disciplina científica, mediante su primera definición académica como "aquella actividad educativa que pretende revelar significados e interrelaciones a través del uso de objetos originales, por un contacto directo con el recurso o por medios ilustrativos, no limitándose a dar una mera información de los hechos” (1957: 10).

Esta base se fue alimentando progresivamente con las investigaciones de importantes teóricos como Ham (1992; 2014), Aldridge (1975), Sharpe (1982), Beck y Cable (1998) o Brochu (2003), orientadas al desarrollo de diversos modelos, técnicas y pautas interpretativas, tanto en recursos naturales como culturales, que permitieran el contacto más adecuado y eficaz con la audiencia. Relativo a cuestiones gubernamentales, destacar la labor de organizaciones como la National Park Service (NPS, 1974) en Norteamérica, y la ICOMOS, que ha marcado las directrices de la IP a nivel internacional en su Carta para la Interpretación y Presentación de Sitios de Patrimonio Cultural (Québec, 2008). En España, por el contrario, sigue siendo una asignatura pendiente, con mucho camino por recorrer, teniendo como mayor referente a Morales (2001) y la Asociación para la Interpretación del Patrimonio (AIP) en materia de metodología interpretativa y su aplicabilidad a espacios naturales y culturales. Solo unos pocos han aportado una visión genérica de unión entre turismo e IP, subrayando a Mendoza, Umbral y Arévalo (2011), y a Bertonatti (2005).

Adentrándonos en el terreno de la interpretación propiamente arqueológica, más específico de nuestra investigación, el campo investigador es más reducido, resaltando los trabajos de González (1998), con el posicionamiento de la IP como medio para la puesta en valor del vestigio y la generación de atracción turística; Villalobos (2005), en referencia a la interpretación del patrimonio sumergido; o Morère (2006) quién expone que, a pesar de que los vestigios son la manifestación física de la pervivencia del pasado, por sí mismos proporcionan muy poca información, salvo para el individuo erudito. Por ende, su visita se hace incomprensible si no se interpreta adecuadamente. Es por ello que cada vez es mayor la implementación de los parámetros de esta disciplina en los diferentes yacimientos arqueológicos, permitiendo el asentamiento progresivo de esta práctica en el panorama turístico-patrimonial español. Se busca únicamente explicar su significado buscando crear una historia científica bien presentada, trabajada y que transcienda a importantes sectores de la población, con unos contenidos científicos e auténticos (Tilden, 2006). Destacando los diferentes enfoques y técnicas de la interpretación, observamos algunos enfoques extremistas basados en criterios de autenticidad, que propugnan evitar cualquier aproximación comercial que lleve a lo multitudinario, defendiendo una simple exposición de los vestigios tras su consolidación, lo que supone, más bien, la ausencia de intervención (Tinard, 1996). Habitualmente las intervenciones que hacen que un yacimiento sea comprensible se pueden referir a señalizaciones, reconstrucciones parciales, itinerarios, servicios guiados, aulas arqueológicas, teatralizaciones, nuevas 
tecnologías o centros de interpretación. Las técnicas utilizadas pueden variar mucho en función de las audiencias, sus conocimientos, la identidad local, y lo que se quiere obtener (Carrier, 1998).

En todos los yacimientos arqueológicos se lleva a cabo algún tipo de interpretación y sería muy largo enumerar todos los ejemplos. Si nos centramos en Grecia, podemos destacar iniciativas como la de la Fundación del Mundo Heleno en materia de programas educativos específicos, aplicaciones multimedia o visitas virtuales; o el ambicioso proyecto de recreación real del Coloso de Rodas, con un museo interpretativo en su interior.

La interpretación es una de las herramientas del Turismo arqueológico, configurado como base de nuestra investigación, puesto que esta esta tipología turística permite marcar el vínculo entre turismo e historia, entendiendo el yacimiento como elemento transmisor del pasado, y la arqueología y su interpretación como la metodología de trabajo utilizada para reconstruirlo, generando así su atractivo turístico (Morère, 2006). Siguiendo los trabajos previos de Tresserras (2004) y Morère y Jiménez (2007), definimos el turismo arqueológico o arqueoturismo como aquellos desplazamientos y actividades culturales y turísticas realizadas teniendo como motivación principal conocer y visitar yacimientos, estructuras o vestigios de cualquier índole, producto de la existencia en los mismos de la actividad humana, teniendo siempre presente las concepciones recogidas sobre patrimonio arqueológico en las leyes estatales y autonómicas. Ballart y Tresserras (2001) y Pérez-Juez (2006) subrayan además la importancia de alcanzar un turismo arqueológico sostenible mediante el adecuado desarrollo de programas de gestión, contemplados siempre desde una perspectiva trasversal, siendo nuestro estudio prueba de ello.

En España, éste continúa siendo una subtipología contemplada dentro del panorama del turismo cultural, con una incipiente coordinación entre los agentes público-privados y una escasa legislación pertinente. Sin embargo, se comienza a observar su integración en los planes de desarrollo turístico mediante estrategias de renovación de imagen, diversificación de la oferta y fortalecimiento de productos turísticos existentes (Tresserras, 2008). Un primer diagnóstico de la realidad turística arqueológica en España la realizaron Morère y Jiménez (2007), analizando la gestión, planificación y políticas concernientes a los yacimientos existentes en las diferentes CC.AA, cuyas conclusiones determinaron la importancia de Cantabria como destino de primer orden, gracias a su labor en Altamira. Sobresalen también en materia de potenciación de este tipo de turismo: Baleares dentro de su plan de patrimonio histórico, Andalucía, con la Red Andaluza de Yacimientos visitables, o la creación de planes de dinamización vinculados a la arqueología en comunidades como Ceuta, Melilla, Murcia, Valencia o Galicia, con su Red de Parques Arqueológicos. Actualmente, gracias a la investigación, interpretación y revitalización de estos espacios, se está mejorando continuamente su accesibilidad y atractivo, generando un arqueoturismo cada vez más consolidado, siendo prueba de ello las inversiones realizadas en el Museo Arqueológico Nacional (MAN) o el Museo Nacional de Arqueología Subacuática (ARQUA); las intervenciones en mejora de equipamientos como en la Red de Parques y Yacimientos de Castilla la Mancha; musealizaciones como la del cementerio judío de Monjüic; o el desarrollo de proyectos específicos como Ibertur, la primera red dedicada al turismo arqueológico nacional, destinada a estudiarlo, promoverlo y preservar sus recursos, así como Arqueotur, derivada de la anterior, que ofrece información detallada de yacimientos visitables, museos y centros de interpretación, fomentando la participación conjunta de los agentes turísticos en relación al patrimonio arqueológico.

A nivel mundial, ha sido la ICOMOS, en su Carta Internacional para la gestión del Patrimonio Arqueológico (Lausana, 1990), quien estableció la necesidad de promover su protección mediante la cooperación entre especialistas de múltiples disciplinas, actuando el turismo como una de ellas. En su "Carta sobre Turismo Cultural" (México, 1999), determinó además la interacción dinámica entre patrimonio y turismo cultural en seis principios, integrando los sitios arqueológicos, para garantizar la sostenibilidad mediante la conservación y la gestión adecuada de estos enclaves y el desarrollo de un turismo de escaso impacto negativo e integrador de la sociedad local. Siguiendo estas premisas, el Instituto Arqueológico de América (AIA), la revista "Arqueology" y la Asociación de Turismo de Aventura (ATTA) elaboraron en 2013 un manual de buenas prácticas tanto para operadores turísticos que desean incorporar sitios arqueológicos en sus paquetes turísticos, como para los turistas que los visitan.

Tomando como premisa esta necesidad interpretativa arqueológica, a la que pretendemos dar respuesta desde un enfoque turístico-patrimonial, es en Grecia donde nos queremos centrar. Grecia, destino por excelencia del Turismo Arqueológico por su historia, su arqueología y su emplazamiento, se vislumbra como nuestro marco espacial, al ser objeto también de conocimiento por parte de fuentes literarias antiguas. 


\section{Turismo en Grecia.}

Apoyándonos en la labor estadística de la Asociación de Empresas Turísticas Griegas (SETE), la Autoridad Estadística Helena (ELSTAT), el Consejo Mundial de Viajes y Turismo (WTTC), el ICEX o el World Economic Forum (WEF) se determinará el entorno turístico griego, el cual, a pesar de la grave recesión económica vivida en el país, se caracteriza por la positividad de sus características, suponiendo una gran contribución al PIB, del 17,3\%, así como al empleo, alcanzando el 19,4\% (WTTC, 2014-2015). Ésta se distribuye de forma irregular a lo largo del año, manifestando una clara estacionalidad turística estival (SETE, 2013). Asimismo, el Ranking 2015 de Competitividad Turística Internacional sitúa a Grecia en el puesto trigésimo primero, siendo sus principales competidores España, Italia y Francia (WEF, 2015).

Analizando la demanda turística (Tabla 1), destacar que Grecia alcanzó su cifra récord con 22 millones de visitantes no residentes en 2014, y unos ingresos anuales de 13.393 millones de euros, con previsiones de crecimiento futuro constante. Por ende, su perfil demandante tiene un carácter mayoritariamente internacional (del 80\%), con un elevado gasto medio individual de casi $608 €$ (ICEX; ELSTAT, 2014). Según su destino de origen, ese turismo procede principalmente de países como Alemania $(11,2 \%)$, Reino Unido (9,5\%), Bulgaria (7\%) y Francia $(6,6 \%)$.

Tabla 1. Principales datos turísticos de demanda según año.

\begin{tabular}{|l|c|c|c|c|}
\hline Llegadas de no residentes desde el extranjero & 2011 & 2012 & 2013 & 2014 \\
\hline Millones de visitantes & 16,427 & 15,518 & 17,920 & 22,033 \\
\hline Ingresos anuales (Millones de $\boldsymbol{\epsilon}$ ) & $10.504,70$ & $10,442,5$ & $12.152,2$ & 13.393 \\
\hline Gasto medio por visitante $(\boldsymbol{\epsilon})$ & 639,48 & 672,93 & 678,13 & 607,86 \\
\hline
\end{tabular}

Fuente: ICEX. ELSTAT

La estancia media es elevada, de 8 días aproximadamente, siendo de 2,3 días en Atenas. En cuanto a la motivación (Gráfico 1), un 84,3\% viaja por vacaciones, seguido de negocios $(5,8 \%)$ y visitas familiares $(3,8 \%)$.

\section{Gráfico 1. Motivación turística según ingresos}

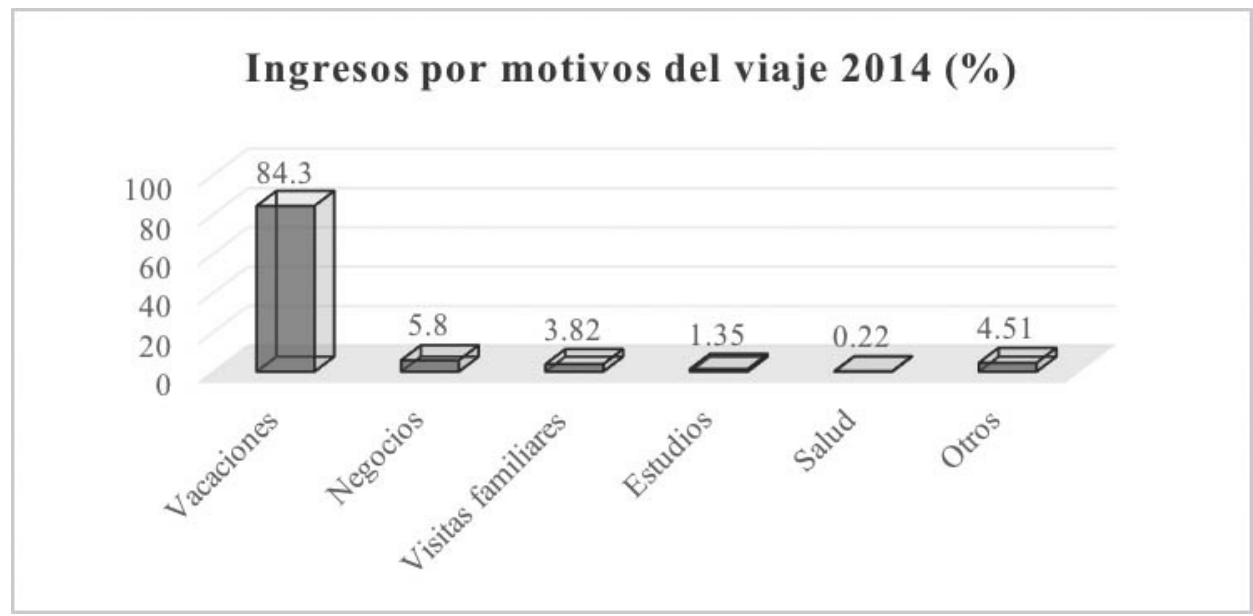

Fuente: Elaboración propia; ICEX (2014).

El transporte aéreo lidera el mercado, con un $63,8 \%$ de las llegadas turísticas, debido a la difícil accesibilidad del país, seguido lejanamente del transporte por carretera (33\%) y el marítimo (3,2\%). Del total de llegadas por aeropuertos, el $29,4 \%$ accede por Atenas, consolidando la importancia turística 
de la capital (ICEX, 2014). Finalmente, las pernoctaciones totales ascendieron a 71,5 millones (6,5 millones corresponden a la región del Ática), con una ocupación del 45,2\%, siendo eminentemente internacionales, lo que denota la importancia del turismo foráneo en destino y la poca movilidad del turismo doméstico (ELSTAT, 2013).

Relativo a la oferta, resaltar la gran diversidad de tipologías turísticas, dominando el mercado el turismo Heliotalasotrópico y el Cultural (Figura 1).

Figura 1. Principales destinos griegos según tipología turística

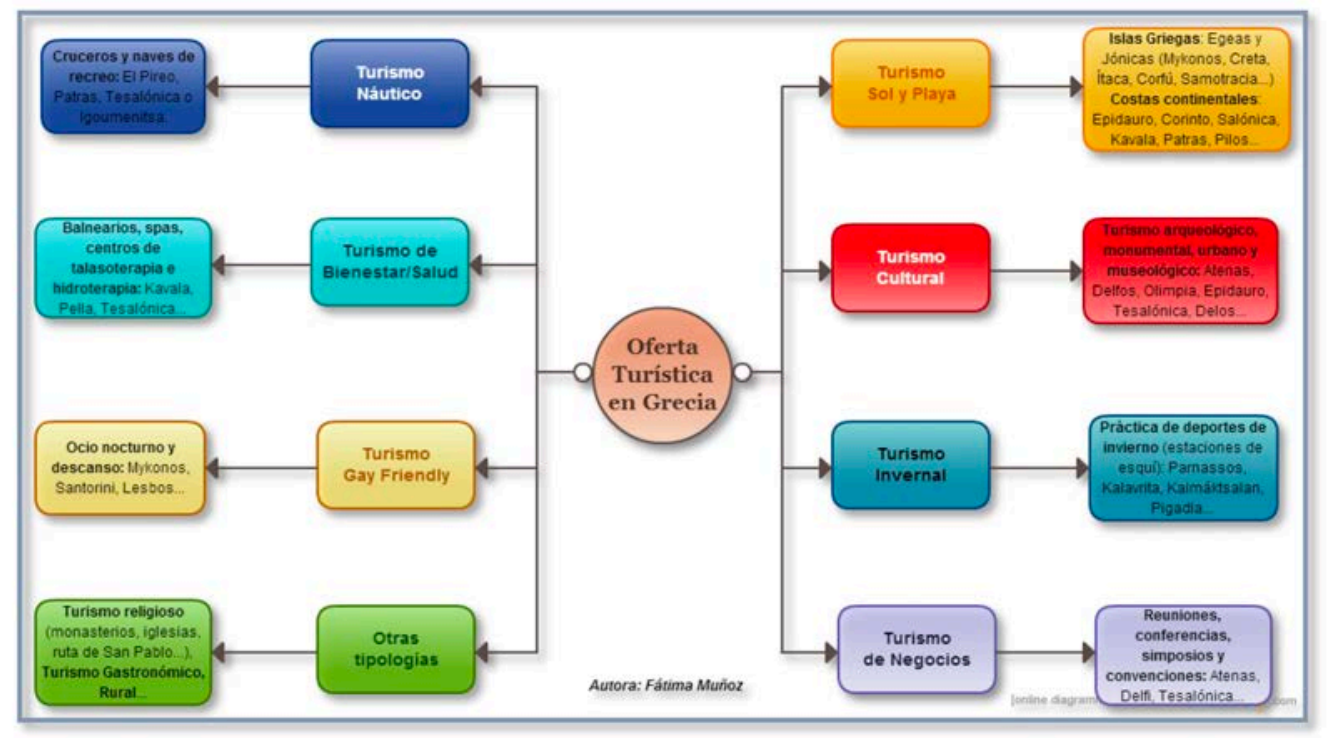

Fuente: Elaboración propia; Guía Azul (2011).

Asimismo, predomina la restauración tradicional sobre la globalizada, con un sector del alojamiento liderado por los hoteles baja categoría (2 y 3 estrellas) y un escaso desarrollo de infraestructuras turísticas extra-hoteleras (SETE; ELSTAT, 2014).

De la figura 1, se deduce que el Turismo arqueológico es una modalidad en Grecia, con entidad propia, configurando nuestro campo específico de análisis.

En Grecia, el Turismo arqueológico, viene determinado por la Plataforma ODYSSEUS del Ministerio de Cultura, donde se encuentran registrados alrededor de 382 yacimientos y 261 museos, junto con las cifras arrojadas por su Instituto Estadístico (ELSTAT):

Tabla 2. Museos y Sitios Arqueológicos: cifras totales

\begin{tabular}{|c|c|}
\hline Museos y Sitios Arqueológicos (ELSTAT) & 2014 \\
\hline \multicolumn{2}{|l|}{ MUSEOS } \\
\hline $\begin{array}{l}\text { Total Visitantes (incluidas entradas } \\
\text { gratuitas) }\end{array}$ & 5.869 .919 \\
\hline Ingresos $(€)$ & 11.793 .726 \\
\hline \multicolumn{2}{|l|}{ SITIOS ARQUEOLÓGICOS } \\
\hline Total Visitantes & 12.954722 \\
\hline Ingresos $(€)$ & 42.869 .819 \\
\hline
\end{tabular}

Fuente: ELSTAT. 
En la tabla 2 se advierte la supremacía de los sitios arqueológicos frente a los museos, tanto en lo relativo a visitantes como ingresos. Tomados los sitios arqueológicos individualmente (Gráfico 2), se observa como lidera el pódium de visitantes la Acrópolis de Atenas con aproximadamente 1,5 millones, seguido lejanamente del yacimiento cretense de Cnosos, con 670.499 visitantes, la Acrópolis de Lindos, con 630.041 y la Antigua Olimpia, con 464.990. El Ágora Ateniense, no recogida por los datos del ELSTAT, tuvo en 2014 unos 639.309 visitantes, con una previsión de crecimiento del 10\% prevista para ese mismo año, según los datos aportados por el área gestora del yacimiento (vid infra). Por ende, el Ágora, pese a su importancia histórica, queda ensombrecida por su competidor más potente, la Acrópolis, al concentrar menor número de visitas.

\section{Gráfico 2. Yacimientos arqueológicos más visitados en 2014}

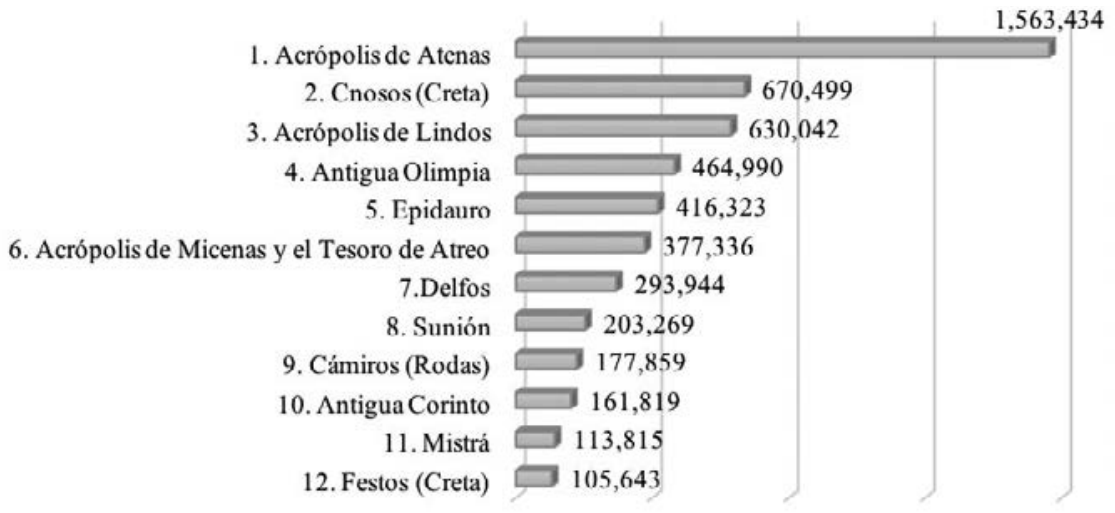

\section{$\square N^{\circ}$ Visitantes 2014}

Fuente: ELSTAT.

Por otro lado, en cuanto a museos (Gráfico 3), son el de la Acrópolis y el Arqueológico Nacional los más visitados, representando el $35 \%$ y $11 \%$ respectivamente de las visitas totales previamente expuestas.

Gráfico 3. Principales museos visitados en 2014

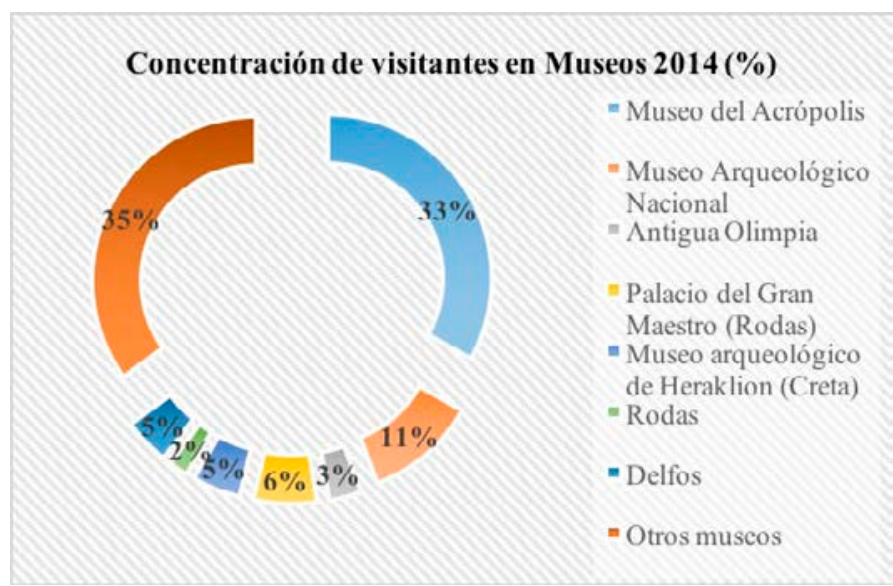

Fuente: ELSTAT. 
El mapa 1 indica los 17 principales yacimientos griegos, seleccionados según dos parámetros: los recursos arqueológicos más visitados según los datos previos del ELSTAT (12 en total); y aquellos catalogados como Patrimonio de la Humanidad (PH) según la UNESCO, pero exclusivamente los arqueológicos, seleccionando de un total de 17, los 10 concernientes a esta tipología. La figura estrellada ilustra los que cumplen ambos parámetros; la romboide los que solo se encuentran entre los más visitados; y la circular los que solo tienen la declaración de la UNESCO ${ }^{1}$.

Un dato concluyente obtenido es el hecho de que llevar la etiqueta de PH no siempre es sinónimo de ser el recurso más visitado, ni garantía de ello. Además, ha permitido discernir la relevancia arqueológica de la capital ateniense, dado que la mayoría de yacimientos analizados son cercanos a la capital.

\section{Mapa 1. Principales yacimientos arqueológicos griegos}

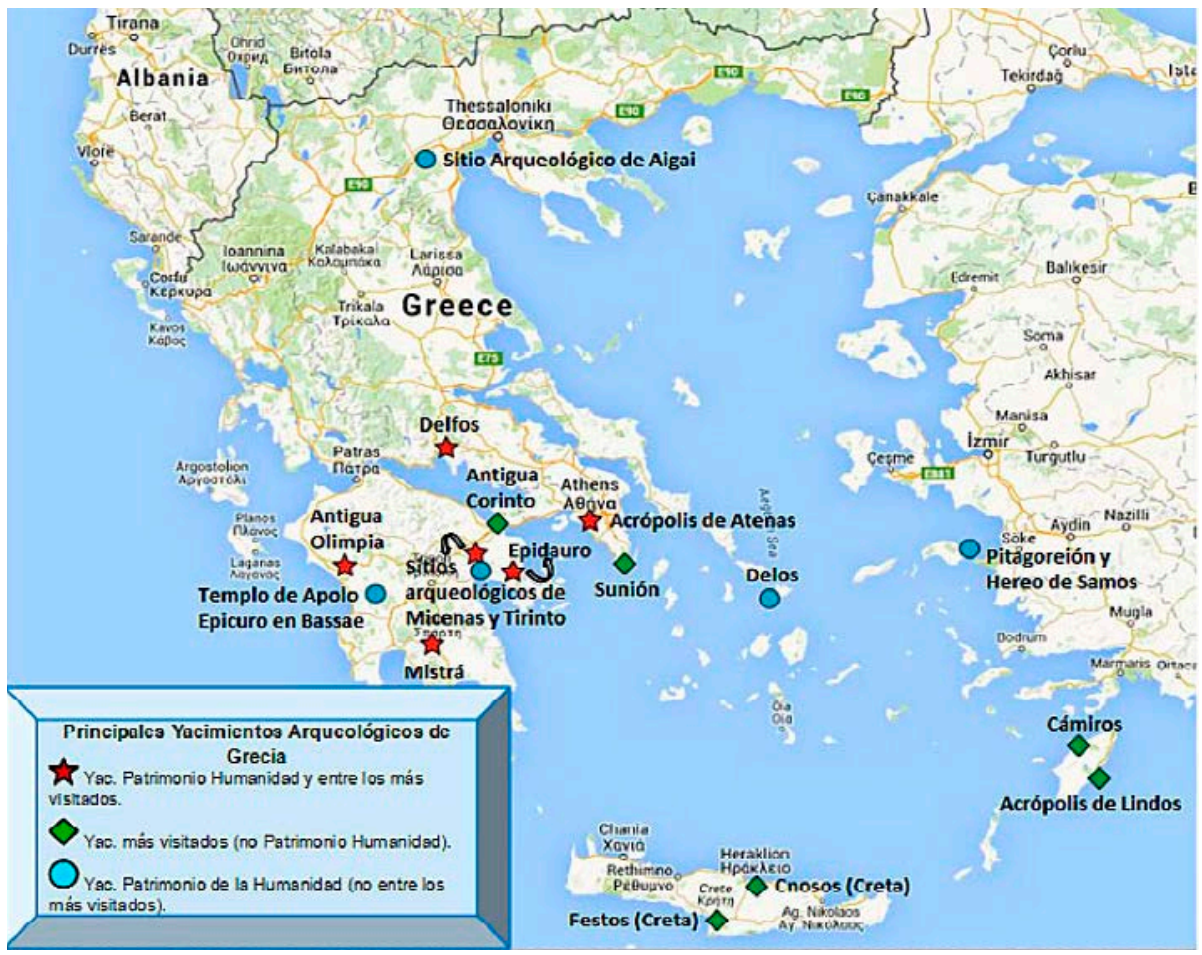

Fuente: Elaboración Propia, a partir de la UNESCO, el ELSTAT y ODYSSEUS.

Todo lo anterior nos lleva a plantearnos la hipótesis y los objetivos de nuestra investigación.

\section{Hipótesis.}

Se parte de la hipótesis de que los destinos turísticos son fruto de una construcción sociocultural a lo largo del tiempo, donde sociedad local y viajeros se convierten en actores activos, por lo que los escritos de viajeros a lo largo de la historia pueden constituir una fuente esencial. El conocimiento profundo de ese proceso permitirá una interpretación patrimonial adecuada que permita impulsar una mejor aproximación de los nuevos destinos, monumentos o yacimientos arqueológicos a la sociedad. La utilización de fuentes primarias históricas, concretamente el legado escrito de Pausanias, se convertirá en el instrumento que permitirá la creación de una interpretación patrimonial auténtica y eficiente, testada a través de su aplicación al Ágora Ateniense, en nuestro caso, en aras de promover un turismo participativo, dotar de significado a este patrimonio arqueológico y alentar su preservación. 


\section{Objetivos.}

Destacamos entre:

A. Generales.

O.G.1. Desarrollar una iniciativa práctica que acerque el turismo al mundo griego antiguo y al patrimonio arqueológico, con la intención de darle significado, dinamizarlo y superar la dificultad de comprensión de su contexto.

O.G.2. Unir antigüedad y contemporaneidad a través de una novedosa propuesta metodológica basada en fuentes literarias primarias de la Antigüedad (Pausanias) y su unión con la visitabilidad turística actual, introduciendo metodología de otros campos científicos en las ciencias del turismo.

\section{B. Específicos.}

O.E.1. Analizar la situación del sector turístico griego, especialmente la dimensión arqueológica, para la contextualización de nuestra propuesta.

O.E.2. Utilizar la Interpretación del Patrimonio como método y modelo para la puesta en valor del Ágora ateniense, con el desarrollo de un discurso cimentado en fuentes antiguas y el diseño de un itinerario interpretativo siguiendo los parámetros de esta doctrina.

O.E.3. Analizar la obra literaria de Pausanias como personaje precursor del turismo griego, transmisor del patrimonio antiguo y fuente indiscutible para el descubrimiento arqueológico.

\section{Metodología.}

Se presenta una tipología de investigación turística llevada a cabo a partir del análisis de fuentes documentales históricas, mediante herramientas y modelos propios del turismo, dentro de un acercamiento híbrido, pero que constituye la base de la propia caracterización del mismo como disciplina científica que, desbordando el marco cerrado de la multidisciplinareidad e interdisciplinareidad, avanza a través de una metodología común entre varias disciplinas, en aras de alcanzar los objetivos holísticos del turismo.

\section{Análisis de fuentes secundarias.}

Integran un complejo vaciado bibliográfico de fuentes documentales, que abarcan desde libros, catálogos bibliográficos múltiples, guías, altas históricos, webs y publicaciones gubernamentales, revistas científicas, y bases de datos, especialmente estadísticas, utilizadas para el análisis del entorno turístico, así como cartográficas y audiovisuales, que han permitido el análisis del recurso y su ponderación en la matriz interpretativa.

\section{Análisis de fuentes primarias: documentos.}

Razón de ser de nuestra investigación, planteamos de forma innovadora el estudio de obras originales, destacando la "Descripción de Grecia" de Pausanias como fuente primaria. Especialmente se ha trabajado con el libro I, que engloba las regiones del Ática y Megáride, desarrollando un inventario ordenado integrador de todos los hitos visitados por el autor y sus características principales.

\section{Modelo interpretativo.}

Toda forma de interpretación, para alcanzar el éxito, debe realizarse mediante una metodológica sistemática, debiendo recurrir, por ello, a la planificación interpretativa. Ésta es un proceso secuencial, dinámico y flexible a cualquier tipo de modificación. Todo ello debe de conducir a un plan, que es el documento resultante de todo proceso de planificación, que nos permitirá la toma de decisiones de cualquier índole y el establecimiento de las prioridades interpretativas. Asimismo, Howie et al. (1975) identifican cuatro niveles de planificación interpretativa: nacional, regional, de lugar (como un sitio histórico, un yacimiento arqueológico, un espacio natural...etc.) y de medios y programas, especificando posteriormente aquellas que conciernen a nuestra propuesta.

La IP se convierte aquí no solo en medio, sino también en método, por lo que a partir de los antecedentes previamente estudiados, se ha creado un modelo interpretativo integrador de cada una de las etapas necesarias en la planificación interpretativa (véase Figura 2), que se implementará en el caso práctico para la interpretación del Ágora. 
Figura 2. Modelo de Planificación Interpretativa.

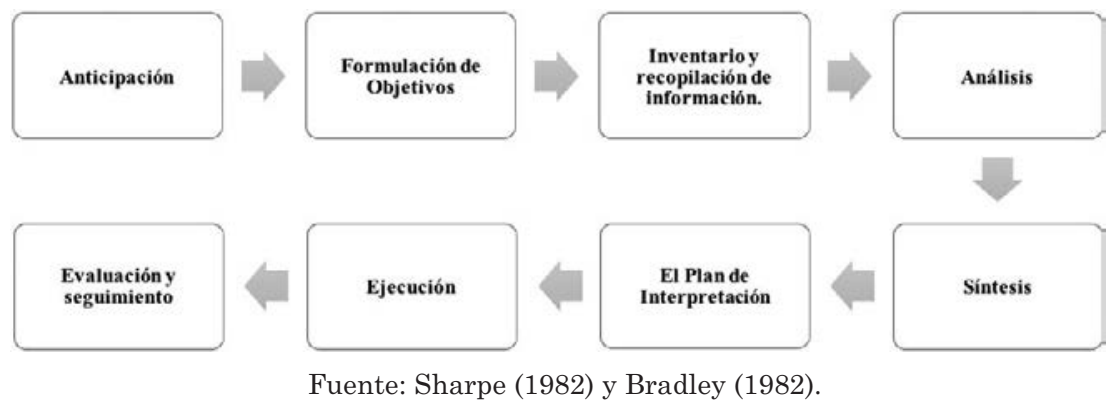

Desglosamos las etapas ilustradas:

I. Anticipación, donde se realiza el reconocimiento del lugar propuesto para la IP.

II. Formulación de los objetivos de la planificación, para ver qué se pretende lograr.

III.Inventario y recopilación de información, a través de la selección de la misma, trabajo de campo y elaboración de fichas de inventario.

IV. Análisis, donde se estudia el recurso y su Índice de Potencial Interpretativo (IPI), mediante una matriz evaluadora que recoge diversos criterios: acceso, singularidad, atractivo, resistencia al impacto, estacionalidad, afluencia turística, información disponible, facilidad de explicación e instalación de los servicios y seguridad de los mismos (Morales y Varela, 1986); se analiza también el visitante, los objetivos, los contenidos y equipamientos a desarrollar, y los medios interpretativos a emplear.

$V$. Sintesis, que resume lo anterior mediante el apoyo de las fichas de inventario confeccionadas.

VI. El plan de interpretación, el cual, debe reflejar múltiples aspectos de contenido: introducción, equipo técnico, evaluación del recurso, características del visitante, discurso, servicios interpretativos, seguimiento y evaluación de los mismos, requerimientos de investigación complementaria, posibles recomendaciones en los servicios, y las referencias y anexos pertinentes.

VII. Ejecución de los servicios interpretativos.

VIII. Evaluación y Seguimiento de las actividades a desempeñar, según los objetivos formulados.

En la fase VI de este modelo, correspondiente al posterior apartado de "Análisis del recurso y diseño general”, se estudiarán cinco elementos indispensables en su contenido: el nivel de planificación, el recurso, el público objetivo, el discurso y la modalidad interpretativa. Éstos se completarán con el desarrollo del itinerario y los servicios complementarios, conformando de esta forma un plan interpretativo que sigue las aportaciones teóricas de Sharpe (1982), Bradley (1982), Morales (2001) y Howie et al (1975).

A su vez, el recurso ha sido analizado tomando en consideración los criterios aportados por Badaracco y Scull (1978) y Morales y Varela (1986) en su matriz evaluadora, donde se integran todos los aspectos críticos concernientes al medio físico, biológico y cultural del lugar interpretado, mediante la aplicación de unos criterios evaluadores que miden su potencial interpretativo. Tras la aplicación de esta matriz, se obtiene un valor numérico, el IPI, qué indica dónde establecer prioridades de operación. Cada uno de los valores asignados en la citada evaluación se ha obtenido mediante el análisis de fuentes secundarias, ante la imposibilidad de realización de trabajo de campo directo. Englobamos aquí el estudio exhaustivo de fuentes fotográficas y audiovisuales, análisis geográfico y topográfico mediante herramientas cartográficas y de fotografía satelital, así como datos reales aportados por el área gestora del propio yacimiento arqueológico y otras bases de datos documentales fiables, como los aportados por la Escuela Americana de Estudios Clásicos en Atenas.

Finalmente, debemos aclarar el hecho de que nuestra investigación, aunque recoge la mayoría de las fases expuestas (a excepción de las dos últimas al tratarse de una propuesta sin implementar) se centra en el desarrollo del discurso interpretativo del Ágora griega y los servicios de apoyo necesarios, utilizando como medio el itinerario, estando estas partes integradas dentro del Plan Interpretativo. El resto de etapas se han reflejado de una forma más escueta para dotar de mayor coherencia al proceso ilustrado, de ahí que tanto el análisis de demanda desarrollado como la evaluación del recurso hayan sido realizados a partir de fuentes secundarias, dado que no han sido objeto prioritario en el proceso investigador. 


\section{Caso Práctico}

\subsection{Pausanias como fuente.}

Las más recientes investigaciones sobre Historia de los Viajes en la Antigüedad manifiestan la multiplicidad de motivaciones, tipologías y modalidades en los desplazamientos, especialmente bien testimoniados a partir de la Grecia antigua por las fuentes escritas (Morère, 2009; Plácido, 2009; Romero, 2009). El ocio, la cultura y la religión albergaban mucha importancia, organizándose los principales desplazamientos alrededor de estas tres grandes motivaciones, junto a otras como las médicas, comerciales o bélicas, como ilustra la figura 3. Todos estos desplazamientos se vieron favorecidos por la consolidación de las leyes griegas de hospitalidad, permitiendo su crecimiento y ocasionando su constante proliferación.

Tienen su origen en la tradición periegetai de viajeros, geógrafos y escritores racionales, cuyos primeros ejemplos serán Hecateo de Mileto y Heródoto (Lévêque, 2006; Domínguez y Pascual, 2006), y cuyo último representante será Pausanias (Andreotti, 2010; Funke, 2010), paradigma por excelencia del viajero y aventurero antiguo, al plasmar su periplo en la obra "Descripción de Grecia".

\section{Figura 3. Cuadro-resumen de las principales tipologías de viaje en la Grecia Antigua.}

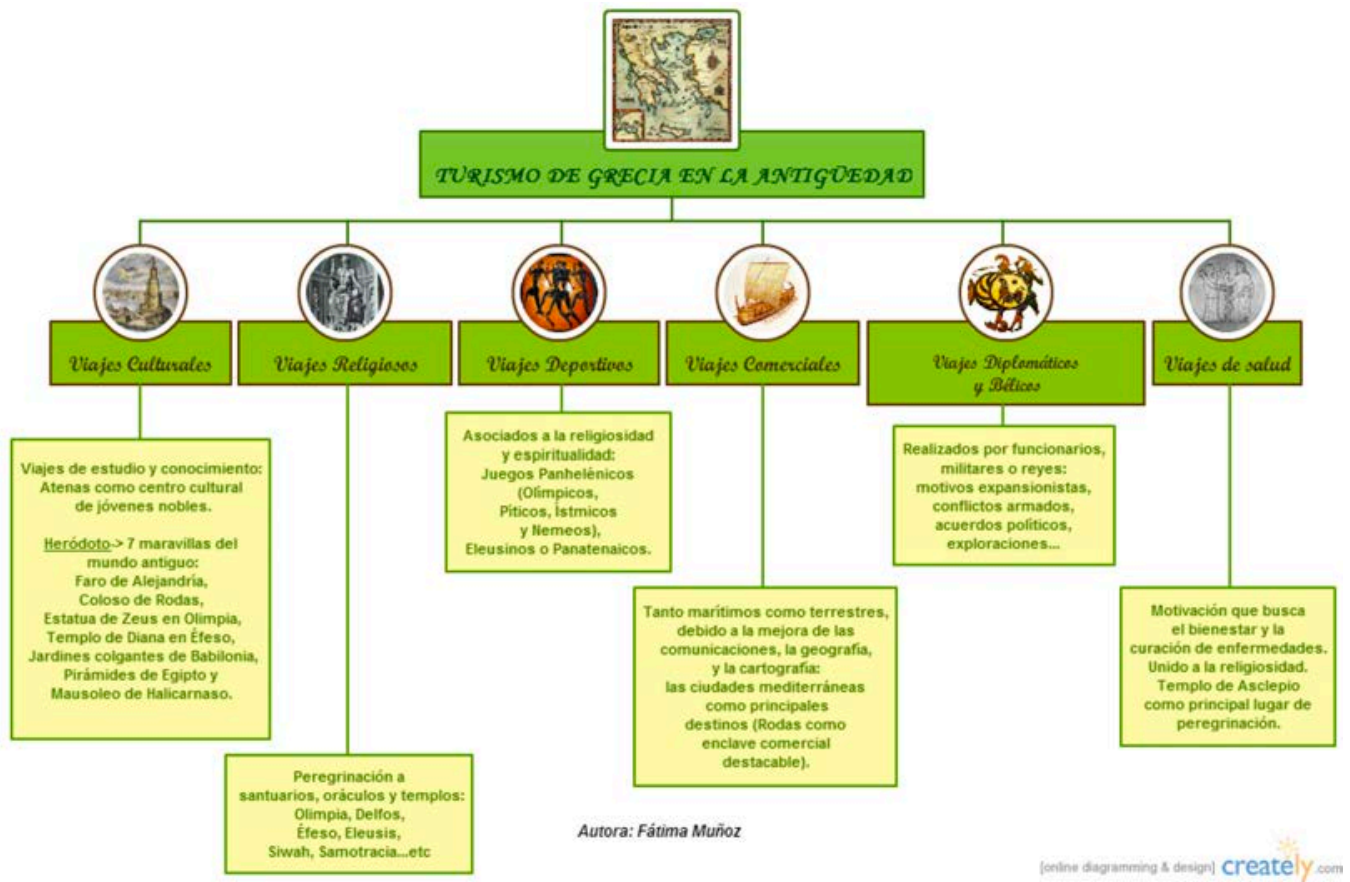

Fuente: Elaboración propia, a partir de Morère, Plácido y Romero (2009).

Así, Pausanias fue un geógrafo e historiador griego del siglo II d.C., autor de la obra Descripción de Grecia, en la cual, a través de 10 tomos, enumera y describe (siguiendo un método estrictamente topográfico) las principales ciudades, monumentos, historia, tradiciones y mitos de varias de las regiones que configuraban la Antigua Grecia continental: Ática y Megáride (Libro I), Corinto y la Argólide (Libro II), Laconia (Libro III), Mesenia (Libro IV), la Élide (Libros V y VI), la Acaya (Libro VII), la Arcadia (Libro VIII), Beocia (Libro IX) y finalmente la Fócide y parte de la Lócride (Libro X). Se ha elegido como fuente por la exactitud y riqueza de las descripciones plasmadas en su discurso, por ser una de las pocas obras del género periegético que ha llegado hasta hoy, considerándose la primera guía de viajes de la historia, y por la credibilidad del autor como fuente histórico-arqueológica. El caso práctico se cimenta en su libro I, concretamente la región del Ática, donde se inserta Atenas. 


\subsection{Visitabilidad de la Atenas de Pausanias vs visitabilidad actual.}

Como base para la posterior interpretación, vamos a llevar a cabo una comparativa entre la visitabilidad de la capital antaño y la era actual. Se comienza con el recorrido que realizaba todo viajero en el s. II d.C. por la capital ateniense, siguiendo en la casuística presente la estela se Pausanias, quién inicia su andadura en el Puerto del Pireo (sudoeste), siguiendo por el camino Hamaxito hasta llegar a la puerta del Dipilon, en la esquina noroeste. Visita el Cerámico exterior o necrópolis, e interior (ya en la ciudad a intramuros), hasta llegar al Ágora de Atenas, continuando su camino hacia el área urbana situada al sureste, donde visita el Olimpeion y gimnasios como el Liceo; para proseguir con la falda meridional de la Acrópolis, el promontorio en sí mismo y después su parte septentrional. Al terminar con éste, se dirige hacia el Aerópago o Colina de Ares, yendo más tarde por la Vía de las Panateneas camino de la Academia de Atenas. Finaliza el itinerario con su visita al resto de Demos del Ática, como Eleusis o Maratón, por citar algunos ejemplos; los montes, como el Pentélico; e islas como Salamina, pasando de esta forma a la siguiente región de destino: Megáride.

El mapa 2 ilustra el recorrido de Pausanias y recoge cada uno de los hitos que configuraban la visitabilidad en época antigua según orden alfabético.

\section{Mapa 2. Visitabilidad de la Atenas antigua según Pausanias}

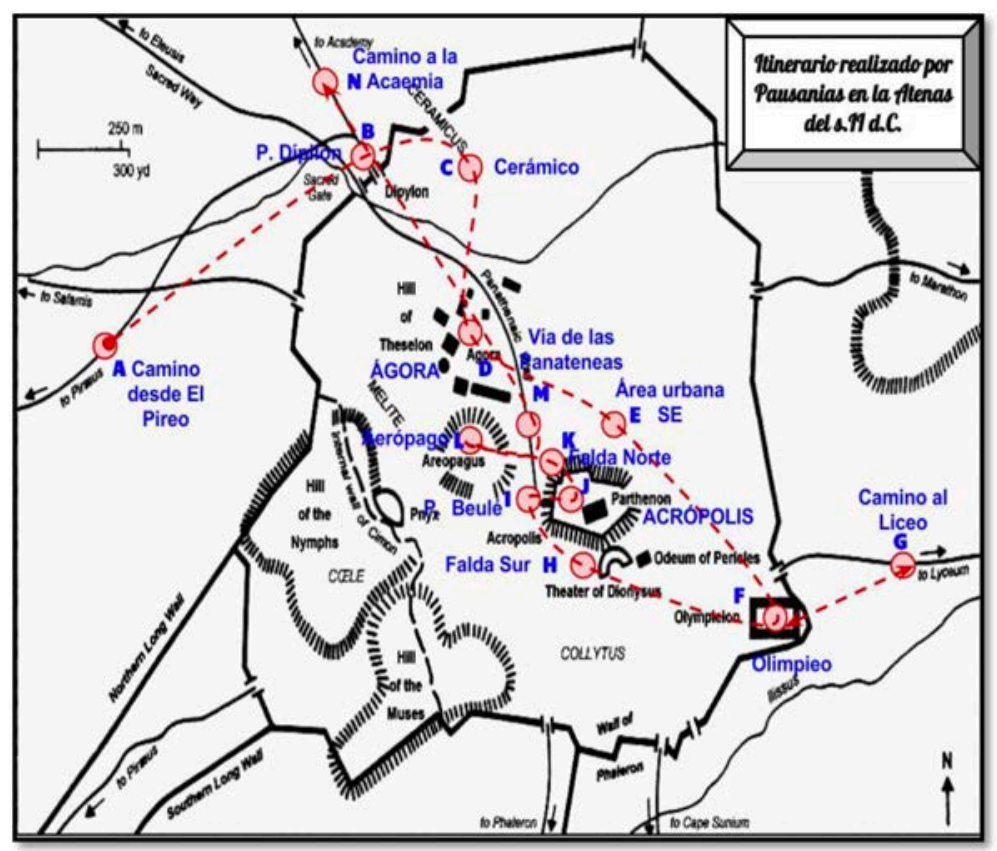

Fuente: elaboración propia, a partir de Pausanias.

Al contrastar el recorrido pausaniano con la visitabilidad de la moderna metrópolis, existe una clara diferenciación, consecuencia de una constante transformación en la planificación urbanística, población y recursos turísticos, producto de la evolución del legado histórico.

El análisis del sector turístico cultural de la capital ha permitido vislumbrar sus enclaves más visitados, situándose la Acrópolis y su museo como hito turístico invicto. Destacan en menor medida las Ágoras griega y romana, el Museo Arqueológico Nacional, el Templo de Zeus Olímpico, el Cerámico y barrios como el Psiri, Monastiraki, Plaka, Phissio y Kolonaki, zonas naturales como el Monte Licabeto, algunas iglesias medievales bizantinas, como la catedral Ortodoxa, y la zona contemporánea, compuesta por las plazas Sigtagma y Omonia, y la Avenida Venizelou, donde se insertan tres de los más significativos edificios neoclásicos: la Academia de Ciencias y Artes, la Universidad y la Biblioteca Nacional. El mapa 3 recoge el Top Ten de los recursos visitables (Guía Azul de Grecia, 2012). 
Mapa 3. Visitabilidad de la Atenas actual.

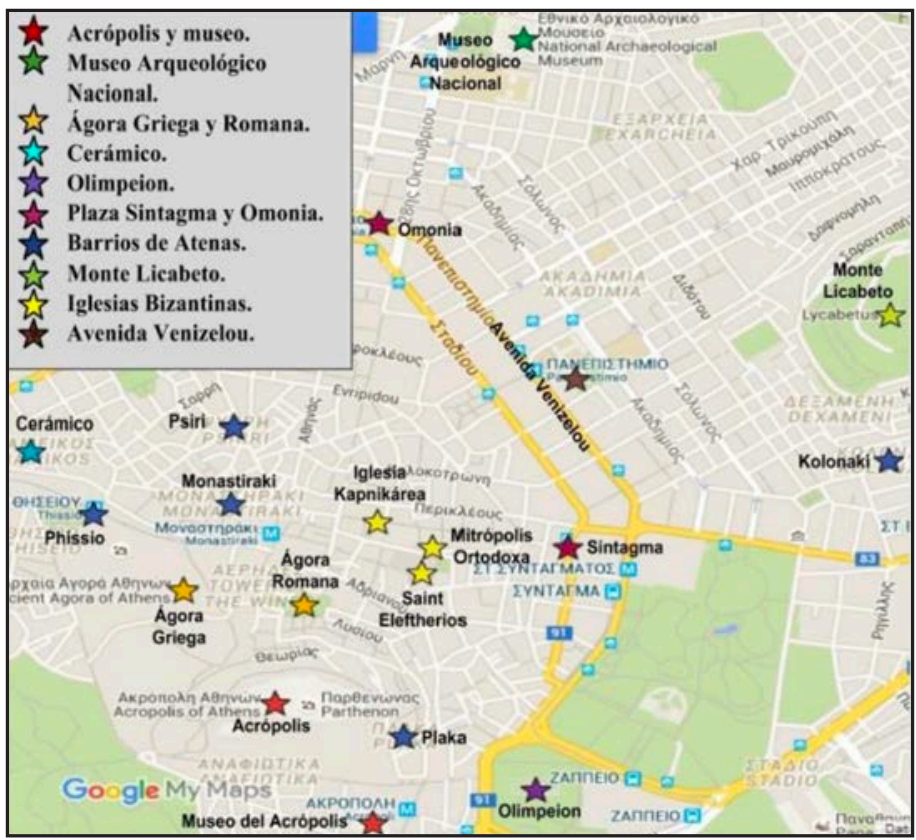

Fuente: elaboración propia, a partir de la Guía Azul (2012).

\subsection{Propuesta interpretativa.}

\section{A. Análisis del recurso y diseño general.}

Con estos elementos, visitabilidad actual y narración de Pausanias, y mediante la metodología del modelo de IP, se confeccionará una propuesta interpretativa dinámica, con la finalidad de aplicar el discurso de un viajero de la antigüedad como es Pausanias, al espacio turístico contemporáneo. Este apartado, junto con el desarrollo del itinerario y sus servicios, se corresponde con la fase VI del modelo o Plan Interpretativo, resaltando el análisis de sus cincos puntos principales, recogidos en la teoría de Sharpe y Bradley (1982).

Nivel de Planificación. Se acoge a dos niveles: al ámbito de planificación de lugar, al centrarse en un área concreta, con el objetivo de ofrecer un servicio interpretativo que pretenda comunicar el significado de este entorno, satisfacer las necesidades del visitante y proteger el recurso; y al ámbito de medios y programas, dado que la interpretación se realizará mediante el diseño de un medio interpretativo específico: el itinerario (Howie et al, 1975).

Recurso. El Ágora griega ateniense, situada al noroeste de la Acrópolis, es actualmente un parque arqueológico marcado por vestigios apenas restaurados. Una pequeña parte del yacimiento está separado del conjunto en sí mismo por las vías del metro entre Atenas y El Pireo. Se encuentra en la parte norte, junto a la calle Adriano, y es la zona arqueológica más recientemente excavada, en 2003. No es habitualmente accesible al público turístico, sin embargo sí permiten visitas grupales previa solicitud. De esta forma, se distinguen dos zonas, que, aunque pertenecientes a un mismo lugar en la antigüedad, se encuentran separadas en la actualidad por barreras físicas.

Para el análisis de su potencial interpretativo, se han utilizado los criterios evaluadores establecidos por Morales y Varela (1986) a partir de la adaptación de la matriz evaluadora de Badaracco y Scull (1978). Mediante unos rangos de puntuación ya preestablecidos, se da un valor a cada criterio analizado 
del recurso ${ }^{2}$, cuya sumatoria da como resultado su índice de potencial interpretativo (IPI), que se puede calificar con tres parámetros: bueno (42-69), regular (21-42) o malo (0-21).

En este caso, se va a evaluar el potencial interpretativo del Ágora como conjunto, no individualmente cada hito (Tabla 3 ).

Tabla 3. Matriz para la Evaluación del Potencial Interpretativo.

\begin{tabular}{|c|c|c|c|c|}
\hline \multicolumn{5}{|c|}{ Matriz para la Evaluación del Potencial Interpretativo } \\
\hline Criterios & Bueno & Regular & Malo & $\begin{array}{c}\text { Valor } \\
\text { Asignado }\end{array}$ \\
\hline Singularidad & $9-7$ & $6-4$ & $3-1$ & 8 \\
\hline Atractivo & 9-7 & $6-4$ & $3-1$ & 8 \\
\hline Resistencia al Impacto & $9-7$ & $6-4$ & $3-1$ & 5 \\
\hline Accesibilidad & $6-5$ & $4-3$ & $2-1$ & 4 \\
\hline Estacionalidad & $6-5$ & $4-3$ & $2-1$ & 5 \\
\hline Afluencia de público & $6-5$ & $4-3$ & $2-1$ & 4 \\
\hline Disponibilidad de Información & $6-5$ & $4-3$ & $2-1$ & 5 \\
\hline Facilidad de Explicación & 3 & 2 & 1 & 1 \\
\hline Pertinencia de Contenidos & 3 & 2 & 1 & 3 \\
\hline Seguridad & 3 & 2 & 1 & 3 \\
\hline Facilidad de Instalación & 3 & 2 & 1 & 1 \\
\hline TOTAL & $\begin{array}{c}\text { Valor Máximo } \\
69\end{array}$ & $\begin{array}{c}\text { Valor Máximo } \\
42\end{array}$ & $\begin{array}{c}\text { Valor Máximo } \\
21\end{array}$ & $\begin{array}{c}\text { Total IPI } \\
47\end{array}$ \\
\hline
\end{tabular}

Fuente: Elaboración propia, a partir de Morales y Varela (1986) y Badaracco y Scull (1978).

La presente evaluación evidencia un IPI bueno, con un resultado de 47 sobre un máximo de 69. Si entendemos el máximo de 69 como el 100\% del potencial, el Ágora tendría un 68,11\% del mismo, obteniendo una calificación casi notable. Sin embargo, ésta no se puede considerar positiva si se tiene en cuenta que está a solo 5 puntos del límite regular. Estos datos permiten detectar la necesidad de actuación, mejora y revitalización del enclave y su interpretación, propósito de nuestra propuesta.

Público. Con el análisis del sector turístico realizado, y la teoría aportada por la Countryside Commission (1979) sobre análisis de usuario, se ha elaborado el subsecuente perfil:

a. Rasgos sociodemográficos: destinado un turista promedio, internacional, con un nivel cultural medio-alto, de procedencia indiferente, y un rango de edad comprendido entre los 20 y 50 años.

b. Rasgos económicos: dirigido a una demanda con capacidad económica estable y un nivel de renta intermedio, teniendo presente el elevado gasto medio que supone de media viajar a este país.

c. Segmento turístico: se integra en la categoría de turismo cultural, y dentro de la misma, en el turismo arqueológico.

d. Grupos: se requerirá la formación de grupos pequeños para una mayor eficiencia en la visita, todos entre 6 y 10 personas, cifra ideal para una ruta guiada (Morales, 2001).

e. Público especial: se trata de una interpretación accesible para personas con diferentes diversidades funcionales físicas y sensoriales, mediante la utilización de recursos específicos expuestos más adelante.

f. Patrones de visita: aunque el yacimiento puede ser visitado a lo largo de todo el año, su afluencia suele ser altamente estacional. Este visitante no pasa más de una mañana o una tarde en el mismo, por lo que la interpretación debe adaptarse a estos indicadores temporales.

Discurso. Tiene un claro carácter histórico con tintes mitológicos, exactamente el mismo que utiliza Pausanias en su narrativa. Se aborda este carácter histórico desde diversas dimensiones, principalmente la artística, social y política, enfatizando así en la diversidad y riqueza del contenido. En cuanto a su 
forma, es conciso, con ejemplos ilustrativos y sin demasiados tecnicismos que deriven en el cansancio o distracción del público objetivo.

Modalidad. Se va a utilizar uno de los máximos exponentes de la IP como medio de transmisión del discurso: el itinerario. Se tratará de su modalidad mixta, que combina la interpretación guiada a través de personal, con una parte autoguiada a partir de recursos de apoyo. Este tipo de servicios permiten adaptar la interpretación a las necesidades de su público, abarcando las ventajas de ambas modalidades de itinerarios: guiados y autoguiados (Sontag, 1971). En cuanto a sus características, destacar que se trata de un itinerario permanente, con necesidad de previa reserva, y una duración total de cuatro horas, incluyendo actividades complementarias y descansos.

\section{B.Itinerario antiguo: tras los pasos de Pausanias por el Ágora.}

A partir de los criterios anteriores, se ha realizado el discurso interpretativo ${ }^{3}$. Se conforma por la historia del Ágora, sus aspectos multiculturales, y su descripción topográfica, para culminar con la ruta pausaniana en este enclave. Entrando a la plaza por la esquina noroeste (1), nuestro viajero gira a la derecha y se concentra en los edificios de la parte occidental, visitando por orden la Stoa Real (2), la de Zeus Eleuterio (3), el Templo de Apolo Patroo (4), el Metrón (5), el Buleuterio (6) y el Tholos (7).

Tras esto, vuelve de nuevo hacia el norte, para describir el períbolo de los Héroes Epónimos (8) y el Templo de Ares (9), situándose ahora en la zona central. Se encamina hacia el sur, visitando el Odeón de Agripa (10), para tomar la Vía Panatenaica hasta la zona suroriental, donde contempla la Fuente (11) y el Eleusinion (12). Obvia la mayoría de recursos de la zona sur, como la Stoa Sur II, la Central, el Edificio Este, la Casa de la Moneda, el Ninfeo o las oficinas cívicas; la este, con la Stoa de Átalo, la Bema, El Monopteros, la Biblioteca de Panteno o la Muralla Valeriana; y en menor medida otros recursos centrales y occidentales, como el Altar de Zeus Agoraios, el Templo de Zeus Phratios, el Strategeion o el Arsenal.

Ulteriormente se desplaza de nuevo a la parte occidental para mostrar el Hefestión (13), bajando después la colina hacia el Santuario de Afrodita Urania (14), la Stoa Poikile (15), así como los altares de Eleo, Aidos, Feme y Horme, no emplazados en el mapa porque todavía no han sido identificados por las labores arqueológicas. Finaliza el recorrido saliendo del recinto por la esquina noreste (16) en dirección a la zona sureste de Atenas (Mapa 4).

\section{Mapa 4. Pausanias en el Ágora}

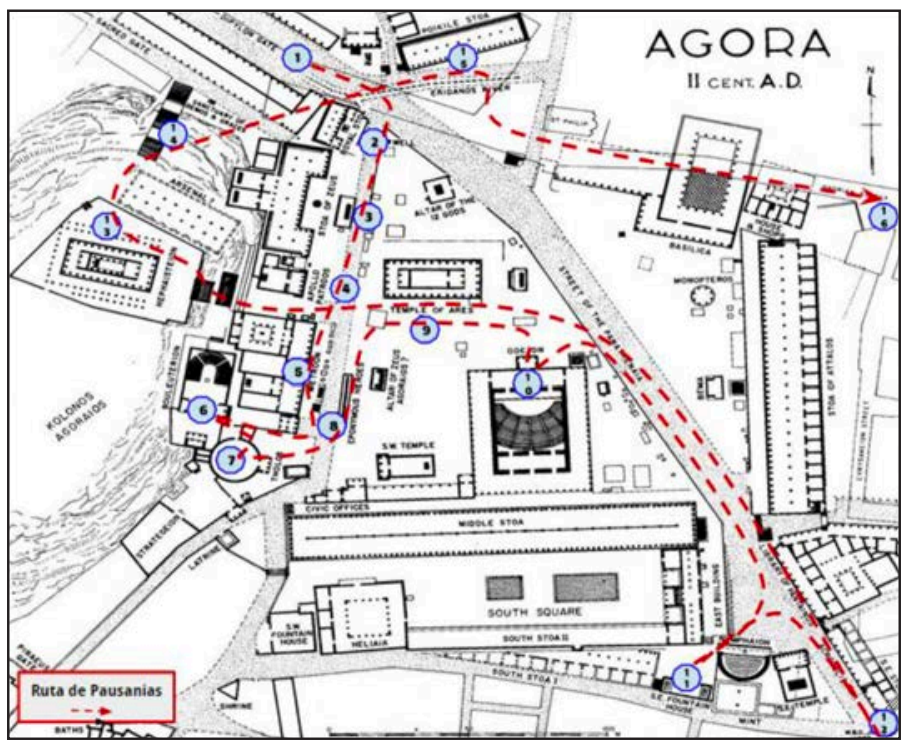

Fuente: elaboración propia, a partir de Camp (1986) y Pausanias. 


\section{Itinerario propuesto actual.}

Estructura e inventario. Aplicando a la actualidad el contenido previo, erigimos una propuesta que integra el recorrido de Pausanias y tiene presente la visitabilidad del espacio arqueológico moderno, siendo enriquecida con elementos significativos obviados por el autor. La estructura del itinerario queda conformada por los siguientes hitos o paradas a realizar por el guía (Tabla 4):

Tabla 4. Itinerario: inventario

\begin{tabular}{ll}
\hline INVENTARIO & \\
\hline 1. Stoa Poikile o Pórtico Pintado. & 16. Odeón de Agripa: Gigantes y Tritones. \\
2. Stoa Real. & 17. Vía Panatenaica. \\
3. Altar de los 12 dioses. & 18. Stoa Media. \\
4. Stoa de Zeus Eleuterio. & 19. Fuente Suroeste. \\
5. Templo de Zeus Phratrios y Atenea Phratria/l & 20. Heliea. \\
Templo de Apolo Patroo. & 21. Stoa Sur II. \\
6. Estatua de Adriano. & 22. Edificio Este. \\
7. Altar de Zeus Agoraios. & 23. Biblioteca de Panteno. \\
8. Héroes Epónimos. & 24. Muralla Valeriana. \\
9. Metrón. & 25. Eleusinion. \\
10. Nuevo Buleuterio. & 26. Mint. \\
11. Tholos. & 27. Fuente Sureste. \\
12. Strategeion. & 28. Stoa Sur I \\
13. Hefestión. & 29. Bema. \\
14. Templo de Afrodita Urania y Santuario de Demos & 30. Monopteros. \\
y Charites. & 31. Stoa de Átalo/ Museo. \\
15. Templo de Ares. & \\
\hline
\end{tabular}

Fuente: Elaboración Propia.

La tabla 4 contiene la totalidad de los hitos descritos en el discurso, omitiendo sólo algunos no identificados o preservados por las labores arqueológicas, como el Arsenal, los altares de Eleo, Aidos, Feme y Horme, el Ninfeo y el Templo de Triptólemo.

Ordenación del trazado. El mapa 5 muestra la organización del itinerario en el espacio, mediante una ordenación numérica para los hitos arqueológicos (figuras circulares), y una ordenación alfabética para la zonificación visitada (figuras estrelladas). La relación numérica coincide con la establecida en el inventario previo, siendo así elementos interdependientes.

\section{Mapa 5. Propuesta de itinerario e hitos visitables.}

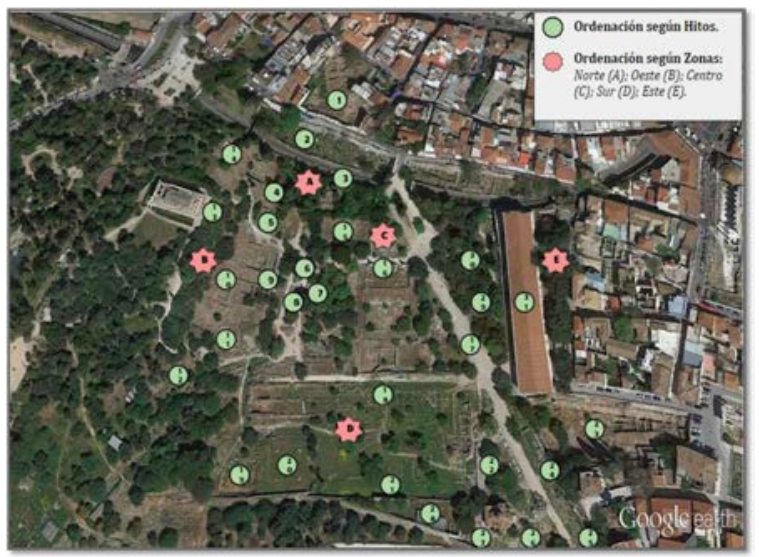

Fuente: elaboración propia. 
Se inicia el itinerario en el área norte del yacimiento, frente a las vías férreas (entre las calles Astiggos y Adriano), donde se encuentra la Stoa Poikile (1). Se continuará con el conjunto en sí mismo, al sur, accediendo por la entrada que brinda la Calle Adriano. Una vez dentro, se comenzará la ruta en la zona noroeste, visitando vestigios como los de la Stoa Real (2) o el Altar de los Doce Dioses (3), para continuar con la vertiente occidental bajando de norte a sur, siendo interpretados la Stoa de Zeus Eleuterio (4), El Templo de Zeus Phratrios y el de Apolo Patroo (5), ambos colindantes, siguiendo con la Estatua de Adriano (6), el Altar de Zeus Agoraios (7) y las Estatuas de los Epónimos (8). Justo enfrente de éstos se contemplará el Metrón y Antiguo Buleuterio (9), el Nuevo (10), situado detrás y el Tholos (11), un poco más al sur.

Una vez situados en la esquina suroeste, se ascenderá por la colina del Kolonos Agoraios, para visitar lo que se especula que fue el Strategeion (12), y terminar con el Hefestión (13). Se descenderá por la senda que desemboca de nuevo en la zona noroeste, al encuentro del Santuario de Afrodita Urania y el de Demos y Charites (14). Se tomará entonces la vía central, para proseguir con la explicación del Templo de Ares (15) y el Odeón de Agripa (16), y salir a la Vía Panatenaica (17). Se bajará por ella en dirección sur, para visitar en primer lugar, la Stoa Media (18) y, de oeste a este, los restos de la Fuente Suroccidental (19), el tribunal de la Heliea (20), la Stoa Sur II (21) y el Edificio Este (22), para proseguir con el extremo suroriental, integrando la Biblioteca de Panteno (23), los vestigios de la Muralla Valeriana (24), el Eleusinion (25), que se encuentra un poco más retirado hacia el sur (aunque en el mapa se ha colocado en la esquina para identificar su presencia), el Mint o Casa de la Moneda (26), la Fuente Suroriental (27) y la Stoa Sur I (28). Se concluirá ascendiendo de nuevo hacia el norte por la vía Panatenaica en dirección este, contemplándose la Bema (29), el Monopteros (30) y la Stoa de Átalo (31), sede del museo arqueológico del Ágora.

Aportaciones al itinerario seguido por Pausanias. Son muchas las similitudes que alberga esta propuesta con el recorrido pausaniano, ya que ambos comienzan por la zona noroeste y continúan por la oeste, para regresar a la zona central y de ahí al sur por la Vía Panatenaica. Sin embargo, hemos obviado los saltos arbitrarios realizados por el viajero, cambiado el orden de visita de los hitos en función de las necesidades físico-geográficas, e introduciendo zonas que él no visita o describe (vertiente sur y este), por ser relevantes para el entorno contemporáneo.

Ordenación del Tiempo. El "timing" general se ha organizado mediante el siguiente cronograma (Tabla 5), realizado como conjunto y no por hito individual interpretado, por la proximidad en la que se encuentran todos ellos.

Tabla 5. Cronograma espacio-temporal

\begin{tabular}{ll}
\hline Desarrollo del Itinerario & Tiempo/Duración \\
\hline Visita al yacimiento del Ágora & 1 hora y 30 minutos. \\
\hline Descanso & 30 minutos. \\
\hline Visita al Museo del Ágora & 1 hora. \\
\hline Actividad Complementaria (a elegir) & 1 hora. \\
\hline
\end{tabular}

Fuente: Elaboración Propia.

\section{Servicios interpretativos.}

Toda IP necesita de recursos complementarios para su adecuado desarrollo, integrando en la medida de lo posible, parámetros de accesibilidad universal (Morales, 2001). Al planificar un itinerario mixto, se tuvo en cuenta aquellos servicios que afectan a la parte guiada, como son el guía intérprete o el intérprete en lengua de signos (ILS); y los relativos a la parte autoguiada, destacando: la creación de puntos explicativos de cada hito, por la obsolescencia y la falta de adaptación de los existentes; señalización de bajo impacto y accesible; modelos estáticos que incluyan las maquetas tiflológicas; exhibiciones de réplicas de elementos arqueológicos manipulables; y efectos de sonido para la recreación ambiental histórica del Ágora. 
Como se observa, se ha considerado la accesibilidad en visita. Por ello, sumamos además otros servicios inclusivos, como las signoguías, una web adaptada, u otras adaptaciones del entorno, como mejoras en la pavimentación y las pasarelas o la posibilidad de alteraciones del recorrido por existencia de tramos inaccesibles.

Finalmente, se han propuesto las líneas generales de diversas actividades complementarias: una de carácter obligatorio, la visita al Museo del Ágora, de una hora de duración; y otras opcionales, incluyendo laboratorios arqueológicos mediante utilización de arqueódromos portátiles; talleres de alfarería helena; animación activa a través de la teatralización de la procesión de las Panateneas, por citar un ejemplo; charlas interpretativas o audiovisuales en 3D, de temática relacionada con el yacimiento. De entre todo el conjunto de actividades opcionales, se elegiría solo una, cuya duración dependerá de sus características y necesidades, no superando nunca el máximo temporal de una hora.

\section{Conclusiones.}

Así pues, tras este análisis y propuesta, querríamos destacar, primeramente su carácter inédito y novedoso, donde la IP se convierte en una herramienta indispensable para superar las barreras imperantes en torno a la dificultad de comprensión del patrimonio arqueológico, dando por ello respuesta al primero de los objetivos generales marcados. Asimismo, cumpliendo con el segundo de los objetivos, hemos llevado a cabo la unión del pasado con el presente a través de la comparación de la visión de un viajero de la antigüedad como es Pausanias, con la propuesta realizada. Así, del análisis de su discurso narrativo determinamos su condición como guía intérprete del pasado y del presente, como viajero indiscutible y fuente irreemplazable para el descubrimiento arqueológico, por lo que al extrapolar su legado a la actualidad se aporta una perspectiva más real y nítida del patrimonio estudiado, permitiendo el desarrollo de un turismo más auténtico. En este sentido, la IP es aquí metodología y modelo de construcción de la propuesta diseñada, donde las fuentes históricas se convierten en fuentes primarias para la investigación turística.

Adicionalmente, se ha trabajado un nuevo espacio de la demanda turística, la específicamente arqueológica, potenciando una subtipología del turismo cultural que aún no ha adquirido la suficiente fuerza para ser catalogada como segmento diferenciado, fomentando así la implicación futura en la misma por parte de las organizaciones, y sirviendo de ejemplo a otros yacimientos arqueológicos. Paralelamente, como contribución significativa al ámbito social, se potencia la sensibilización en materia de accesibilidad turística y universal, al considerarla para la desarrollo de un turismo arqueológico para todos, y por ende, de una sociedad más inclusiva.

Por todo ello, la metodología seguida, basada en la unión entre patrimonio, turismo e interpretación, puede resultar una fórmula primordial para conseguir una conservación patrimonial eficiente y un desarrollo turístico sostenible, siendo altamente recomendable su integración en este sector. En cuando a las implicaciones más relevantes del proyecto destacamos: en su vertiente gubernamental, la posibilidad de su aplicación práctica futura; y en la académica, la apertura de nuevas e innovadoras líneas de investigación turística, ya que aplica a las ciencias del turismo una metodología procedente de otras disciplinas científicas, mediante el uso de fuentes literarias e históricas, permitiendo así crear productos diferenciados, auténticos, y adecuadamente interpretados.

Culminamos resaltando que, con todo lo previamente reflejado, se ha dado respuesta a la hipótesis planteada, aceptando el hecho de que las fuentes primarias literarias antiguas permiten la creación de un discurso interpretativo legítimo y veraz, dotando de un significado auténtico y coherente al patrimonio arqueológico, revalorizándolo, y fomentando así un turismo más dinámico e interactivo con el público, que sensibilice en materia de respeto y conservación.

\section{Bibliogafia}

Aldridge, D.

1975. Guide to countryside interpretation. Part I: Principles of countryside interpretation and interpretive planning. Great Britain: Countryside Commission for Scotland.

Alonso Villalobos, C.

2005. "La interpretación y el patrimonio histórico sumergido: un problema conceptual". Boletín de Interpretación, 12: 6-5. 
Andreotti, G.

2010. "Algunos apuntes sobre la naturaleza de la geografía griega". En Marco Simón, Pina Polo y Remesal Rodríguez (Eds), Viajeros, peregrinos y aventureros en el mundo antiguo (pp. 13-24). Barcelona: Publicacions i Edicions Universitat de Barcelona.

Archaeological Institute of America (AIA) \& Adventure Travel Trade Association (ATTA).

2013. Guide to Best Practices for Archaeological Tourism. Recuperado Octubre 2, 2015 desde https:// www.archaeological.org/tourism_guidelines

Asociación para la Interpretación del Patrimonio (AIP).

2017. Boletín de Interpretación. Recuperado Abril 18, 2017, desde http://www.interpretaciondelpatrimonio. com/boletin/index.php/boletin

Association of Greek Tourism Enterprises (SETE).

2013. Tourism Statistics. Recuperado Julio 2, 2015, desde http://old.sete.gr/EN/TOURISM/Statistics/

Badaracco, R. J., y Scull, J.

1978. "Megascale Interpretive Planning". The Interpreter, 10 (3): 4-10.

Ballart, J., y Tresserras, J.

2001. La Gestión del Patrimonio Cultural. Barcelona: Ariel.

Beck, L., y Cable, T.

1998. Interpretation for the 21stCentury - Fifteen Guiding Principles for Interpreting Nature and Culture. Champaign, Illinois: Sagamore Publishing

Bertonatti, C.

2005. “Interpretación y turismo: ¿nos interesa dejar un mensaje al turista?”. Boletín de Interpretación, 12: 2-4.

Bradley, G. A.

1982. "The Interpretive Plan". En G. Sharpe (ed.), Interpreting the Environment. London: Wiley \& Sons, Inc.

Brochu, L.

2003. Interpretive Planning: The 5-M model for successful planing projects. Fort Collins, Colorado: The National Association for Interpretation. InterpPress.

Camp, J.M.

1986.The Athenian Agora. Excavations in the Heart of Classical Athens. London: Thames and Hudson Ltd. Carrier, C.

1998. “Teoría y prácticas de la interpretación”. IPHA, 25: 140-146.

Countryside Commission.

1979. Interpretive Planning. Advisory Series No. 2.

Domínguez, A.J., y Pascual, J.

2006. Atlas Histórico del Mundo Griego Antiguo. Madrid: Editorial Síntesis.

Ediciones GAESA.

2011-2012. Guía Azul de Grecia. Madrid: Autor.

Foundation of the Hellenic World.

2015. Historical and Archaeological Research. Recuperado Octubre 20, 2015, desde http://www.ime.gr/ fhw/index.php?lg=2\&state=pages\&id=85

Funke, P.

2010. "Pausanias un die griechischen Heiligtümer un Kulte". En Marco Simón, Pina Polo y Remesal Rodríguez (Eds), Viajeros, peregrinos y aventureros en el mundo antiguo (pp. 219-226). Barcelona: Publicacions i Edicions Universitat de Barcelona.

González Méndez, M.

1998. "El vestigio como atracción del turismo, la interpretación como atracción del vestigio". Anales de Prehistoria y Arqueología, 13-14: 289-299.

Ham, S. H.

1992. Interpretación Ambiental: Una guía práctica para gente con grandes ideas y presupuestos pequeños. Colorado: North American Press.

Ham, S. H.

2014. Interpretación - Para marcar la diferencia intencionadamente. España: Asociación para la Interpretación del Patrimonio.

Hellenic Ministry of Culture, Education and Religious Affairs.

1995-2015 ODYSSEUS-Cultural Heritage. Recuperado Julio 7, 2015, desde http://odysseus.culture. gr/index en.html 
Hellenic Statistical Authority (ELSTAT).

2015. Statistical Themes. Recuperado Julio 4, 2015, desde http://www.statistics.gr/

Hernández, F. y Rojo, M.C.

2012. Museografía didáctica e interpretación de espacios arqueológicos. Asturias: Ediciones Trea.

Howie, R., MacFarlane, J., y Woods, J.

1975. The Approach to Interpretive Planning (or The Joy of Planning). Interpretation and Extension

Division. Ottawa: Parks Canada.

ICOMOS.

1990. Carta Internacional para la gestión del Patrimonio Arqueológico. Lausana, Suiza: Autor.

ICOMOS.

1999. Carta sobre Turismo Cultural. La gestión del Turismo en los sitios con Patrimonio Significativo.

México: Autor.

ICOMOS.

2008. Carta para la Interpretación y Presentación de Sitios de Patrimonio Cultural. Québec: Autor.

Lévêque, $\mathrm{P}$.

2006. Tras los pasos de los dioses griegos. Madrid: Ediciones Akal.

Mendoza Ontiveros, M.M., Umbral Martínez, M. E., y Arévalo Moreno, M. N.

2011. "La Interpretación del Patrimonio, una herramienta para el profesional del turismo". El Periplo

Sustentable, 20: 9-30.

Mills, E.

1920. The Adventures of a Nature Guide. Garden City: Doubleday, Page and Company.

Morales, J.F., y Varela, M.I.

1986. El Índice del Potencial Interpretativo (IPI): Un aporte a las futuras demandas de los futuros parques y a lo que aún resta en los actuales. Actas del I Congreso Nacional de Parques Naturales. Sevilla: Junta de Andalucía.

Morales Miranda, J. F.

2001. Guía Práctica para la Interpretación del Patrimonio. El arte de acercar el legado natural y cultural al público visitante. Sevilla: Junta de Andalucía. Consejería de Cultura. Empresa Pública de Gestión de Programas culturales.

Morère Molinero, $\mathrm{N}$.

2006. "Turismo e Historia: formación e información en el turismo. Un estado de la cuestión". Revista de Análisis Turístico, 2 (2): 86-102.

Morére Molinero, N., y Jiménez Guijarro, J.

2006. “Análisis del Turismo Arqueológico en España. Un estado de la cuestión”. Estudios Turísticos, 171: $115-139$

Morère Molinero, N.

2009. "Hacia un Turismo en la antigüedad". En editorial Centro de Estudios Ramón Aceres (Ed.), Viajes en el Mediterráneo Antiguo (pp. 193-214). Madrid: Editorial Centro de Estudios Ramón Aceres.

Muir, J.

1896. "The national parks and forest reservations". Sierra Club Bulletin, 1(7): 271-284.

Muñoz Tejero, F.

2015. Interpretación Turística del Ágora Ateniense según la obra "Descripción de Grecia" de Pausanias

(Tesis de Máster no publicada). Universidad Rey Juan Carlos, España.

National Park Service (NPS).

1974. A personal Training Program for Interpreters. USA: NPS.

Obispo Benlloch, E.

2015. Estudio de Mercado. El mercado del turismo en Grecia 2015. Madrid: ICEX.

Pausanias.

1994. Descripción de Grecia. Libro I: Ática y Megáride. Introducción y notas de Herrero Ingelmo, M.C.

Madrid: Editorial Gredos.

Plácido Suárez, D.

2009. "Viajes y viajeros de la Grecia Clásica". En editorial centro de estudios Ramón Aceres (Ed.),

Viajes en el Mediterráneo Antiguo (pp.69-76). Madrid: Editorial Centro de Estudios Ramón Aceres.

Pérez-Juez, A.

2006. Gestión del Patrimonio Arqueológico. Barcelona: Ariel. 
Romero Recio, M.

2009. "Viajes del Mundo Helenístico". En editorial centro de estudios Ramón Aceres (Ed.), Viajes en el

Mediterráneo Antiguo (pp.77-92). Madrid: Editorial Centro de Estudios Ramón Aceres.

Sharpe, G.

1982. Interpreting the environment (2nd ed.). London: John Wiley and Sons, Inc.

Sontag, W.H.

1971. "Forethought and Planning Yield a Better Interpretive Trail". En Mahaffey, B. (Ed.), Environmental

Interpretation. USA: Dept. of Recreation and Parks, Texas A \& M University.

G. Starr, C.

1974. Historia del Mundo Antiguo. Madrid: Akal Editor.

The American School of Classical Studies at Athens.

2015. ASCSA Digital Collections. Recuperado Septiembre 24, 2015, desde http://ascsa.net/research?v=default The American School of Classical Studies at Athens.

2015. Athenian Agora Excavations. Recuperado Septiembre 24, 2015, desde http://www.agathe.gr/

Tilden, F.

2006. La interpretación de nuestro patrimonio. Sevilla: Asociación para la Interpretación del Patrimonio (AIP).

Tinard, Y.

1996. .Turismo. Economía y gestión. Barcelona: Bosch.

Tresserras, J.

2004. "El arqueoturismo o turismo arqueológico: un paso más para la valorización del patrimonio arqueológico". Boletín GC, 9: 2-7.

Tresserras, J.

2008. “Turismo Arqueológico”. En AECIT (Ed.), La Actividad Turística Española en 2007 (Edición 2008).

Madrid: Editorial Universitaria Ramón Aceres.

UNESCO.

2015. World Heritage List. Recuperado Noviembre 3, 2015, desde http://whc.unesco.org/?cid=31\&mode=table World Travel and Tourism Council (WTTC).

2015. Travel and Tourism. Economic Impact 2015. Greece. London: Autor.

World Economic Forum (WEF).

2015. The Travel \& Tourism Competitiveness Report 2015. Geneva: Autor.

\section{Notas}

1 Aclarar que la UNESCO recoge la declaración de los sitios arqueológicos de Micenas y Tirinto como una unidad, siendo recogidas por separado para ilustrar el hecho de que Micenas si incluye ambos parámetros, pero Tirinto no, solo es Patrimonio de la Humanidad, de ahí que se contabilicen 11 declaraciones UNESCO en el mapa y no las 10 reales.

2 La asignación de valores en esta matriz parte del análisis del recurso mediante fuentes secundarias documentales, estadísticas y fotográficas, ante la imposibilidad de evaluación directa propia. Véase Metodología.

3 No se ha desarrollado el todo discurso interpretativo por motivos de espacio. El texto completo puede encontrarse en Muñoz Tejero, F. (2015). Interpretación Turística del Ágora Ateniense según la obra "Descripción de Grecia" de Pausanias (Tesis de Máster no publicada). Universidad Rey Juan Carlos, España. 